\title{
Mobile phone radiation alters proliferation of hepatocarcinoma cells
}

\author{
Elcin Ozgura*, Goknur Guler ${ }^{\text {a }}$, Gorkem Kismali ${ }^{\mathrm{b}}$, Nesrin Seyhan ${ }^{\mathrm{a}}$ \\ ${ }^{a}$ Department of Biophysics and Gazi Non-Ionizing Radiation Protection Center, Faculty of Medicine, Gazi University, Ankara, \\ Turkey \\ ${ }^{b}$ Department of Biochemistry, Faculty of Veterinary Medicine, Ankara University, Ankara, Turkey
}

\section{ARTICLE INFO}

\section{* Correspondence to:}

Elcin Ozgur

Department of Biophysics and Gazi Non-Ionizing Radiation Protection Center, Faculty of Medicine, Gazi University, Ankara, Turkey

e-mail: elcinozgur@gazi.edu.tr

\section{Keywords:}

Electromagnetic field

Hippocampus

Histopathological examination

Locomotor activities

\section{ABSTRACT}

This study investigated the effects of intermittent exposure (15 min on, $15 \mathrm{~min}$ off for 1, 2, 3 or 4 hrs) to Enhanced Data rates for Global System for Mobile Communication Evolution (GSM-EDGE) modulated radiofrequency radiation (RFR) at $900 \mathrm{MHz}$ and $1800 \mathrm{MHz}$ frequencies on the viability of the hepatocarcinoma cells (Hep G2). Hep G2 cell proliferation was measured by a colorimetric assay based on the cleavage of the tetrazolium salt [2-(4-Iodophenyl)-3-(4-nitrophenyl)-5-(2,4-disulfophenyl)-2H-tetrazolium] (WST-1) by mitochondrial dehydrogenases in viable cells. Cell injury was evaluated by analyzing the levels of lactate dehydrogenase (LDH) and glucose released from lysed cells into the culture medium. Morphological observation of the nuclei was carried out by 4,6-diamidino-2-phenylindole (DAPI) staining using fluorescence microscopy. In addition, terminal deoxynucleotidyl transferase deoxyuridine triphosphate (dUTP) nick end labeling (TUNEL) assay was performed to confirm apoptotic cell death. It was observed that cell viability, correlated with the LDH and glucose levels, changed according to the frequency and duration of RFR exposure. Four-hour-exposure produced more pronounced effects than the other exposure durations. 1800-MHz RFR had more impact on cell viability and injury of Hep G2 than the RFR at $900 \mathrm{MHz}$. Morphological observations also supported the biochemical results that most of the cells showed irregular nuclei pattern as a marker of late stage apoptosis using the DAPI staining, as well as TUNEL assay which shows DNA damage especially in the cells after 4 hrs of exposure to 1800$\mathrm{MHz}$ RFR. The results showed that proliferation of Hep G2 cells increased after 1 hour of exposure whereas a decrease was observed after four hours of-exposure to the $1800-\mathrm{MHz}$ radiation. The $900-\mathrm{MHz}$ radiation had no significant effect on cell proliferation after 1 hour of exposure, but a decrease was observed after $4 \mathrm{hrs}$ of exposure. Further studies will involve other frequency bands of RFR and longer duration of exposure.

J. Exp.Clin. Med., 2013; 30: 273 